\title{
Survey of Patient Knowledge, Attitudes and Practices Regarding ENT Pathologies in a Tertiary Health Care Facility in West Africa
}

\author{
Diallo Alpha Oumar1, Diallo Oumar Raphiou², Fadegnon Sénami Héléna1, \\ Diallo Mamadou Aliou ${ }^{3 *}$, Dabo Ismaël1, Sinayoko Alimou' ${ }^{1}$ \\ ${ }^{1}$ ENT \& CFS Department, Ignace Deen National Hospital, Conakry, Guinea \\ ${ }^{2}$ Department of Odontostomatology and Maxillofacial Surgery, Donka National Hospital, Conakry, Guinea \\ ${ }^{3}$ ENT \& CFS Department, Donka National Hospital, Conakry, Guinea \\ Email: ^dalphao@hotmail.com
}

How to cite this paper: Oumar, D.A., Raphiou, D.O., Héléna, F.S., Aliou, D.M., Ismaël, D. and Alimou, S. (2021) Survey of Patient Knowledge, Attitudes and Practices Regarding ENT Pathologies in a Tertiary Health Care Facility in West Africa. International Journal of Otolaryngology and Head \& Neck Surgery, 10, 164-172.

https://doi.org/10.4236/ijohns.2021.103017

Received: March 7, 2021

Accepted: May 17, 2021

Published: May 20, 2021

Copyright $\odot 2021$ by author(s) and Scientific Research Publishing Inc. This work is licensed under the Creative Commons Attribution International License (CC BY 4.0).

http://creativecommons.org/licenses/by/4.0/

\begin{abstract}
The ENT pathologies are not well known to the populations of our developing countries. This lack of knowledge leads certain subjects to have attitudes and practices that favor their occurrence and/or their aggravation. The objective of this study was to assess the knowledge and describe the attitudes and practices of patients facing ENT pathologies at the Conakry Hospital and University Center (CHU). This was a prospective, descriptive study lasting six months (June-November 2018). Among the 1410 patients who had consulted in the department during the study period, 1102 had participated in the survey, or $78.16 \%$ of cases. The mean age of the patients was $39.3 \pm 17.3$ years, predominantly female, for a sex ratio of 0.75 . The majority of patients were of university education (41.02\%) and civil servants (38.66\%) represented the dominant socio-professional layer. Rhino-sinusitis (30.85\%) and ear infections $(20.14 \%)$ were the most common pathologies. Almost a third (32.85\%) of respondents had no knowledge of behaviors harmful to ENT health. More than half $(52.45 \%)$ of the patients did not know of any factors favoring the occurrence of ENT pathologies. The therapeutic orientation had been made towards modern medicine in $63.52 \%$ against $4.54 \%$ for traditional medicine. The choice of self-medication concerned $31.94 \%$ of patients. This survey showed that patients have limited knowledge of ENT pathologies as well as the attitudes and practices likely to favor their occurrence. However, a multicenter study involving a larger proportion of patients will confirm these data.
\end{abstract}

\section{Keywords}

Knowledge, Attitudes, Practices, ENT, Conakry 


\section{Introduction}

The incidence of ENT pathologies is different depending on the regions of the world and the age of the patients. While in northern countries, tumor and allergic conditions are the most frequent, in developing countries, infectious diseases represent the leading cause of ENT consultations [1]. These pathologies constitute a real public health problem because of their frequency and the high cost of their management [1]. Several African studies, as well in West Africa, in Central Africa, as in Europe, have shown that they occupy a significant part of the medical activity of consultations leading to multiple recourses to symptomatic therapies (in particular the prescription antibiotics) for which the cost-effectiveness ratio has not been established [1] [2] [3] [4]. These pathologies are not well known to the populations of our developing countries. This lack of knowledge leads certain subjects to have attitudes and practices that favor their occurrence and/or their aggravation. A better understanding of the social context and the behaviors of patients suffering from ENT pathologies is therefore essential to develop educational interventions adapted to our health system, in order to reduce the morbidity and mortality linked to these pathologies. Hence the initiation of this work, which aimed to assess the knowledge and describe the attitudes, practices of patients facing ENT pathologies at the Conakry Hospital and University Center.

\section{Materials and Methods}

This was a prospective study of descriptive type, lasting six months, from June 1 to November 30, 2018. We included in this study all patients aged 15 years and over, treated in our service for a non-cancerous ENT pathology, and having accepted to answer our questionnaire. For the purposes of the study, we designed a questionnaire whose validity and reliability had been tested before the start of the survey. This made it possible to retain the age, sex, profession, residence, level of education, reasons for consultation, knowledge of ENT pathologies (good/average/bad), attitudes and practices in the face of his pathologies was administered. We also studied the primary therapeutic orientation of patients (self-medication, traditional medicine, modern medicine) through their care path.

It should be noted that for age, we have deliberately chosen not to include in this study patients aged 0 to 14 years and ENT cancers. This methodological criterion was adopted to avoid response bias in the assessment of knowledge, attitudes and practices of patients, which are aspects relating to the cognitive and behavioral domains. Thus, compliance with this criterion guarantees us results that are directly attributable to patients, that is to say, their actual perception on the subject.

The data collected was analyzed using Epi Info software (version 7.2.0.1). The informed consent of each patient was obtained as well as the authorization of the ethics committee of the Faculty of Health Sciences and Techniques of the Cona- 
kry University Hospital.

\section{Results}

Out of 1410 patients who consulted in the department during our study period, 1102 patients were selected to participate in the study, i.e. $78.16 \%$ of cases. The average age of our respondents was $39.3 \pm 17.3$ years with extremes of 15 and 95 years. We noted a female predominance of $56.99 \%(n=628)$ with a sex ratio of 0.75 (Table 1).

The ENT pathologies encountered during our study period were rhino sinusitis and ear infections, representing respectively $30.85 \%(\mathrm{n}=340)$ and $20.14 \%(\mathrm{n}$ $=222$ ) of cases (Table 2 ).

Table 1. Breakdown of patients seen in the ENT department of the Ignace Deen National Hospital from June 1 to November 30, 2018 according to their socio-demographic profile.

\begin{tabular}{|c|c|c|}
\hline Socio-demographic data & Effective & Percentage \\
\hline \multicolumn{3}{|l|}{ Sex } \\
\hline Feminine & 628 & 56.99 \\
\hline Male & 474 & 43.01 \\
\hline \multicolumn{3}{|l|}{ Origin } \\
\hline Conakry & 1046 & 94.92 \\
\hline Interior of the country & 56 & 5.08 \\
\hline \multicolumn{3}{|l|}{ Educational level } \\
\hline Unschooled & 242 & 21.96 \\
\hline Primary & 112 & 10.16 \\
\hline Secondary & 296 & 26.86 \\
\hline University & 452 & 41.02 \\
\hline \multicolumn{3}{|l|}{ Profession } \\
\hline Driver & 20 & 1.81 \\
\hline Trader & 162 & 14.70 \\
\hline Farmer & 18 & 1.63 \\
\hline Pupil/Student & 206 & 18.69 \\
\hline Official & 426 & 38.66 \\
\hline Imam & 8 & 0.73 \\
\hline Household & 160 & 14.52 \\
\hline Worker & 72 & 6.53 \\
\hline Retirement & 30 & 2.72 \\
\hline
\end{tabular}


Table 2. ENT pathologies diagnosed.

\begin{tabular}{|c|c|c|}
\hline & Effective & Percentage \\
\hline \multicolumn{3}{|l|}{ Otological pathologies } \\
\hline Ear infections & 222 & 20.14 \\
\hline Cerumen cap & 134 & 12.15 \\
\hline Deafness & 44 & 3.99 \\
\hline Foreign body of the External acoustic meatus & 12 & 1.08 \\
\hline \multicolumn{3}{|l|}{ Rhino-sinus pathologies } \\
\hline Rhino-sinusitis & 340 & 30.85 \\
\hline Rhinitis & 166 & 15.06 \\
\hline Fracture of the nasal bones & 6 & 0.54 \\
\hline Polyp & 12 & 1.08 \\
\hline \multicolumn{3}{|l|}{ Oral-pharyngo-laryngeal pathologies } \\
\hline Rhino-pharyngo-tonsillitis & 94 & 8.52 \\
\hline Rhino-pharyngitis & 56 & 5.08 \\
\hline Pharyngitis & 38 & 3.44 \\
\hline Pharyngo-tonsillitis & 32 & 2.90 \\
\hline Laryngitis & 28 & 2.54 \\
\hline Tonsillitis & 26 & 2.35 \\
\hline \multicolumn{3}{|l|}{ Cervico-facial pathologies } \\
\hline Goitre & 10 & 0.90 \\
\hline Parotiditis & 8 & 0.72 \\
\hline Cellulite & 4 & 0.36 \\
\hline Mastoiditis & 2 & 0.18 \\
\hline
\end{tabular}

Only $32.85 \%$ of respondents $(n=362)$ knew at least one attitude or practice not favorable to ENT health. Complications of ENT pathologies recognized by patients being related to attitudes and practices were respectively hearing disorders in $46.28 \%(n=510)$ of cases, vocal disorders in $1.81 \%(n=20)$ of cases and olfactory disorders in $0.93 \%$ of cases.

The factors favoring the occurrence of ENT pathologies listed by our patients are grouped together in Table 3. These were mainly exposure to Allergens $36.6 \%$ $(\mathrm{n}=404)$, untimely cleaning of the ear $24.86 \%(\mathrm{n}=274)$ and slapping $21.41 \%(\mathrm{n}$ =236) of case.

Faced with ENT pathology, 63.52\% $(n=700)$ of the respondents had a positive attitude, going immediately to see a health facility. However, $31.94 \%$ ( $\mathrm{n}=$ 352) had performed self-medication and $4.54 \%(n=50)$ had preferred to seek traditional medicine. 
Table 3. Patient knowledge of the factors favoring the occurrence of ENT pathologies.

\begin{tabular}{ccc}
\hline & Effective & Percentage \\
\hline No & $\mathbf{5 7 8}$ & $\mathbf{5 2 . 4 5}$ \\
Exposure to Allergens & 404 & 36.66 \\
Sntimely cleaning of the ear & 274 & 24.86 \\
Slaps & 236 & 21.41 \\
Excessive consumption of cold foods & 192 & 17.42 \\
Smoking/Alcoholism & 58 & 5.26 \\
Lack of oral hygiene & 28 & 2.54
\end{tabular}

\section{Discussion}

This is a hospital series, thus justifying the small size of the sample. It would have been more interesting to report the results of this work to the general population. On the other hand, the prospective nature of this study associated with its center of interest focused on the knowledge, attitudes and practices of patients in the face of ENT pathologies make it a relevant work. The results of this study document two major inseparable aspects of care which, until then, had not been addressed in our country. It is about patients' knowledge of ENT pathologies and their practical attitude to these pathologies. This will allow a better understanding of the context of occurrence of these pathologies in our practice context and the development of interventions aimed at reducing the incidence of these pathologies in the population.

The mean age of our patients was higher than that reported by Hounkpatin S.H.R. [3] in Benin, ie 24 years. This could be explained by the deliberate choice not to include patients aged 0 to 14 years in this study.

We noted a female predominance with a sex ratio of 0.75 . Our result was similar to that of Njifou-NjimahA et al. [2] in Cameroon and Attifi $\mathrm{H}$ et Coll. [1] in Guinea, which reported 0.74 and 0.78 respectively. However, the data in the literature have never shown the influence of gender in the occurrence of ENT pathologies [4] [5].

The rhino-sinus pathologies were the most observed in our respondents. This would be linked to the conjunction of external favorable factors linked to our exercise context (in particular tropical climatic conditions, the low socio-economic level of the population and self-medication) and intrinsic (genetic, congenital, anatomical, etc.) [6]. They were followed by ear infections which can also be, in the majority of cases, the direct result of negative attitudes and practices very common in our societies, such as untimely cleaning of the ear (external acoustic meatus) by inappropriate objects.

More than half of our respondents had no knowledge of the external contributing factors and negative attitudes or practices that could explain the occur- 
rence of ENT pathologies and/or their complications. Thus, giving patients appropriate and correct information and eliciting positive attitudes towards ENT pathologies and their curability is essential for the effective control of the disease [7]. This is why researchers, health workers and policy makers increasingly recognize that encouraging patients to play a more active role in their medical care improves the quality and efficiency of health care, and ultimately, health outcomes at the population level [7] [8]. Health education is therefore an important tool to promote patient empowerment.

Faced with ENT pathology, more than half of the respondents $(63.52 \%)$ had a positive attitude, going immediately to consult a health structure, probably due to the good knowledge of the various health structures in the country by the respondents. themselves or those around them (friend, parents, etc.). This may also be linked to the fact that health education on the various ENT pathologies is regularly provided through the local media.

However, more than a third of the respondents had resorted to self-medication or traditional medicine. These were attitudes that should be avoided because they could undermine control efforts through poor, high-risk practices or by non-compliance with treatment (dosage, compliance, etc.).

The reasons for choosing this medicine seem to revive the debate about its place in our health system, because, according to certain studies, traditional medicine, with good supervision, would gain in popularity throughout Africa [8] [9]. Indeed, on this continent, almost $80 \%$ of the population would use traditional medicine. This choice would be favored by the cultural conviction of the availability of drugs and their accessibility to all sections of the population [10].

Also, the main reasons for self-medication would be linked to the fact that the diseases were considered minor by the patients because the majority of the drugs used by our respondents came from pharmacies and other approved places of sale [11]. However, we must continue to promote good public health attitudes and practices in order to sensitize populations to the danger of self-medication.

\section{Conclusion}

This survey made it possible to understand that the patients consulting in our service have moderate knowledge about ENT pathologies with several identified knowledge gaps. Although attitudes towards these conditions and essential health care were generally positive, respondents did not report consistently sound prevention practices. However, a multicenter study involving a larger proportion of patients will confirm these data, in order to initiate patient-centered interventions to improve the knowledge, attitudes and practices of populations in our developing countries.

\section{Conflicts of Interest}

The authors declare no conflicts of interest regarding the publication of this paper. 


\section{References}

[1] Attifi, H., Hmidi, M., Boukhari, A., Touihem, N., Kettani, M., Zalagh, M. and Messary, A. (2014) Expérience oto-rhino-laryngologique de l'hôpital Marocain de campagne en Guinée Conakry. The Pan African Medical Journal, 19, Article No. 40. https://doi.org/10.11604/pamj.2014.19.40.4908

[2] Njifou-Njimah, A., Ndjock, R., Essama, L., Moby, H., Motah, M., Fonyam, V., Bitang, L.J., Zambo, O.J.C., Ndjolo, A. and Ebana, M.C. (2013) Profil de la pathologie ORL à l'Hôpital Laquintinie de Douala. Médecined Afrique Noire, 60, 415-418.

[3] Hounkpatin, S.H.R., Avakoudjo, F., Lawson-Afouda, S., Yemadjro, F.S.R., Adjibabi, W., Vodouhè, S.J. and Hounkpè, Y.Y.C. (2011) Prévalence des affections ORL au centre hospitalier régional du Borgou dans le nord Bénin. The Revue AfricainedOto-Rhino-Laryngologieet de Chirurgiecervico-faciale, 11, 2-3.

[4] Lavaud, F. and Dutau, G. (2012) Comment est vécue la rhinite allergique par les patients. Revue Française d' Allergologie, 52, 427-428.

https://doi.org/10.1016/j.reval.2012.08.001

[5] Bopaka, R.G., Jabri, H., Janah, H., El Khattabi, W. and Afif, H. (2015) Connaissances et comportements des patients atteints de la rhinite allergique en consultation à Casablanca. Revue Française d Allergologie, 837, 1-3.

[6] Ezizyi, J.A.E., Amusa, Y.B. and Akinpelu, O.V. (2010) Prevalence of Otorhinolaryngological Diseases in Nigerians East and Central. South African Journal of Surgery, 15, 85-89.

[7] Kigozi, N.G., Heunis, J.C., Engelbrecht, M.C., Janse van Rensburg, A.P. and van Rensburg, H.C.J.D. (2017) Tuberculosis Knowledge, Attitudes and Practices of Patients at Primary Health Care Facilities in a South African Metropolitan: Research towards Improved Health Education. BMC Public Health, 17, Article No. 795. https://doi.org/10.1186/s12889-017-4825-3

[8] Canivet, M. and Lecocq, D. (2019) Entre tradition et modernité, médecine traditionnelle et soins infirmiers en Côte d'Ivoire. Revue de I Infirmiere, 68, 27-29.

https://doi.org/10.1016/j.revinf.2018.11.006

[9] Abbo, C., Odokonyero, R. and Ovuga, E. (2019) A Narrative Analysis of the Link between Modern Medicine and Traditional Medicine in Africa: A Case of Mental Health in Uganda. Brain Research Bulletin, 145, 109-116.

https://doi.org/10.1016/j.brainresbull.2018.07.018

[10] Kakondja, S., Bahaya, A., Cirimwami, B. and Museme, W.C. (2017) Etude des facteurs favorisants le recours des patients à la Médecine traditionnelle dans la ville de Bukavu. Cah Ceruki, 53, 78-90.

[11] Olajide, T.G., Aremu, K.S., Esan, O.T., Dosunmu, A.O. and Raji, M.M. (2018) Topical Ear Drop Self-Medication Practice among the Ear, Nose, and Throat Patients in IdoEkiti, Nigeria: A Cross-Sectional Study. Annals of African Medicine, 17, 70-74. https://doi.org/10.4103/aam.aam_28_17 


\section{Investigation Sheet $\mathbf{N}$ :}

\section{General Information}

Age: Gender: Female / _ / Male / __ I

Profession:

Residence: Conakry / _ _ interior of the country / _ /.

Profession:

Education level: No schooling / _ / Primary / _ /, Secondary / _ /, University / _ $/$.

\section{Reasons for Consultation}

1) Ear:

Earache I _ / Ear pruritus I _ / Otorrhea / _ / otorrhagia / _ / Vertigo / _ I Ringing / _ / Fullness / _ / Plug / _ / Foreign body / _ / Swelling / _ I Hearing loss / _ / Other (explain, list)

2) Nose:

Rhinorrhea / _ / Nasal obstruction / _ / Nasal pruritus / _ / Bleeding / _ I Nasal mass / _ / Sneezing / _ / Anosmia / _ / Hyposmia / _ / Cacosmia / _ / Other (Specify)

3) Oral cavity and oropharynx:

Odynophagia / _ / Dysphagia / _ / Hemmage / _ / Trismus / _ I

Pharyngeal pruritus / _ / Snoring / _ / Halitosis / _ I

Foreign body / _ / Other (Specify)

4) Larynx:

Dyspnoea / _ / Dysphonia / _ / Aphonia / _ / Cough / _ I

Foreign body / __ / Other (Specify)

5) Neck:

Cervical lymphadenopathy / _ / Adeno-phlegmon / _ / Cervical swelling / _ / Other (Specify)

6) Salivary glands:

Parotid swelling / _ / Ageusia / _ / Hypogeusia / _ /

Sensation of bitter taste / _ / Other (Specify)

Diagnostic:

\section{Knowledge Assessment}

1) Do you have any knowledge about ENT pathologies? : Yes No /__

2) If Yes, how will you appreciate this knowledge? : Good / _ / Average / _ / $\mathrm{Bad} /{ }_{-} /$

3) Can you give us some ENT pathologies? : Yes No /__

Do you know of any behaviors that are not favorable to ENT health?:

Yes No /

4) If Yes, which ones?

5) Do you know of any handicaps linked to ENT diseases? : Yes No /__ 
6) If Yes, which ones?

Auditory / __ / Vocal / _ / Olfactory / _ / None / _ /

Other (Specify)

7) What are the risk factors favoring the occurrence of ENT pathologies? Allergens / _ / Smoking / alcoholism / __ / Slapping / _ / Cold / _ /

Diabetes / _ / High blood pressure / _ / Immunodeficiency / _ /

Untimely cleaning of the ears / _ / Lack of oral hygiene / __ /

Other (Specify )

8) Do you know the structures for the care of ENT pathologies in the city?

9) How did you get into our service?

\section{Assessment of Attitudes towards ENT Pathologies}

1) What is your primary therapeutic orientation in the event of an ENT pathology?

Self-medication / __ / Modern medicine / _ / Traditional medicine / _ /

2) What motivated your choice of treatment?

Lack of time / _ / Better support / _ / Accessibility / _ / Lack of means / _ I Advice from relatives / friends / _ / Other (Specify) 